\title{
Dispersion for Injection/Infusion Dosage
}

\section{Form}

National Cancer Institute

\section{Source}

National Cancer Institute. Dispersion for Injection/Infusion Dosage Form. NCI

Thesaurus. Code C149442.

Sterile liquid preparation consisting of two or more phases of which at least one is dispersed in the liquid phase, intended for administration by injection or infusion. 